\title{
Numerical Age Computation of the Antarctic Ice Sheet for Dating Deep Ice Cores
}

\author{
Bernd Mügge $^{1}$, Alexey Savvin ${ }^{1}$, Reinhard Calov ${ }^{2}$, and Ralf Greve ${ }^{1}$ \\ ${ }^{1}$ Institut für Mechanik III, Technische Universität Darmstadt, Hochschulstraße 1, \\ D-64289 Darmstadt, Germany \\ ${ }^{2}$ Potsdam-Institut für Klimafolgenforschung, Postfach 601203, D-14412 Potsdam, \\ Germany
}

\begin{abstract}
The application of two different methods for the computation of the age of ice is discussed within the frame of numerical ice sheet modelling. The first method solves the purely advective equation for the age field in the Eulerian frame, which requires the addition of a numerical diffusion term to stabilize the solution and therefore produces arbitrary results in a near-basal boundary layer. The second method makes more efficient use of the simplicity of the equation in the Lagrangian frame by tracing particle paths in the flowing ice body, and it does without artificial diffusion.

We compute the age field for the Antarctic ice sheet with both methods for a time-dependent simulation driven by a 242200 year surface temperature history derived from stable isotope data of the Vostok deep ice core, and discuss the differences of the age computation schemes. Emphasis is put on two regions: (i) western Dronning Maud Land (DML), where reconnaissance for a deep ice core within the European Project for Ice Coring in Antarctica (EPICA) is currently carried out, and (ii) the eastern part of central East Antarctica with the deep-ice-core locations Vostok and Dome C (the former completed, the latter currently drilled within EPICA). The Eulerian scheme provides good results except for the lower parts of the ice sheet where the numerical diffusion falsifies the computed ages. The particletracing scheme does not show this shortcoming; however, it yields ages generally somewhat too small because it does not yet account for the time-dependence of the ice flow.
\end{abstract}

\section{Introduction}

Ice cores are a valuable archive of the past climate containing data on the $\mathrm{CO}_{2}, \mathrm{CH}_{4}$ and dust contents of the atmosphere as well as proxy data on the atmospheric temperature. One major problem is to relate the depth of the ice core to the age of the ice, which is called dating of ice cores. In principle it is possible to measure the age stratigraphically by following the seasonal cycle of suitable tracers; however, this method is limited by ice-layer thinning. Therefore it is common practice to date the deeper parts of an ice core with the help of an ice-flow model. The traditionally applied flow models are of the Dansgaard-Johnson type [3]. The parameters of these one-dimensional, purely vertical models are adjusted to the conditions in the borehole using the 
ice velocity and snowfall derived from the borehole as input, and steady-state conditions are usually assumed.

In this study, we discuss an alternative approach to ice-core dating based on the application of a transient, three-dimensional, dynamic/thermodynamic ice-sheet model (SICOPOLIS, Greve [6]). This model computes the englacial velocity field and therefore need not be driven by velocity measurements in the borehole. A further advantage is that an ice core can be dated preliminarily before it has actually been drilled.

Two different age-computation schemes are implemented in SICOPOLIS:

- Solution of the advective age equation in the Eulerian frame with the aid of some numerical diffusion (Huybrechts [11], Calov et al. [2]).

- Tracing of ice particles along their flowlines, connected with the age computation in the Lagrangian frame (Mügge [16]).

We compare both methods for a simulation of the Antarctic ice sheet. The attention is hereby focussed on two regions, namely (i) western Dronning Maud Land (DML), where ongoing field work prepares an ice core within the European Project for Ice Coring in Antarctica (EPICA, Jouzel et al. [14]), and (ii) the eastern part of central East Antarctica, where the ice cores Vostok (completed) and Dome C (EPICA, currently drilled) are situated (Fig. 1). For Vostok, the computed age profiles are further compared with the "Geophysical Metronome Time Scale" provided by Salamatin et al. [18].

\section{Modelling of the Antarctic Ice Sheet}

\subsection{Ice-sheet model SICOPOLIS}

SICOPOLIS is a 3-d dynamic/thermodynamic ice-sheet model based on the continuum-mechanical theory of polythermal ice masses $[1,5,8,9]$. It simulates the time-dependent extent, thickness, velocity, temperature, water-content and age for a grounded ice sheet in response to external forcing. Further, possible basal layers of temperate ice (ice at pressure melting point) are detected with high vertical resolution by fulfilling the Stefan-type conditions at the cold-temperate-transition surface. External forcing is specified by (i) mean annual air temperature above the ice, (ii) surface mass balance (accumulation, surface melting), (iii) sea level surrounding the ice sheet and (iv) geothermal heat flux from below. A more detailed description of SICOPOLIS can be found in Greve [6], Greve et al. [7].

The model domain for the Antarctic ice sheet consists of a $5341 \times 4796 \mathrm{~km}$ rectangle in the stereographic plane with standard parallel $71^{\circ} \mathrm{S}$, spanned by Cartesian coordinates $x, y$ (the vertical coordinate is $z$ ). Horizontal resolution is $109 \mathrm{~km}$, so that the domain is discretized by $50 \times 45$ grid points. Vertical resolution is 51 grid points in the cold-ice column, 11 grid points in the temperate-ice column (if existing) and 11 grid points in the lithosphere 


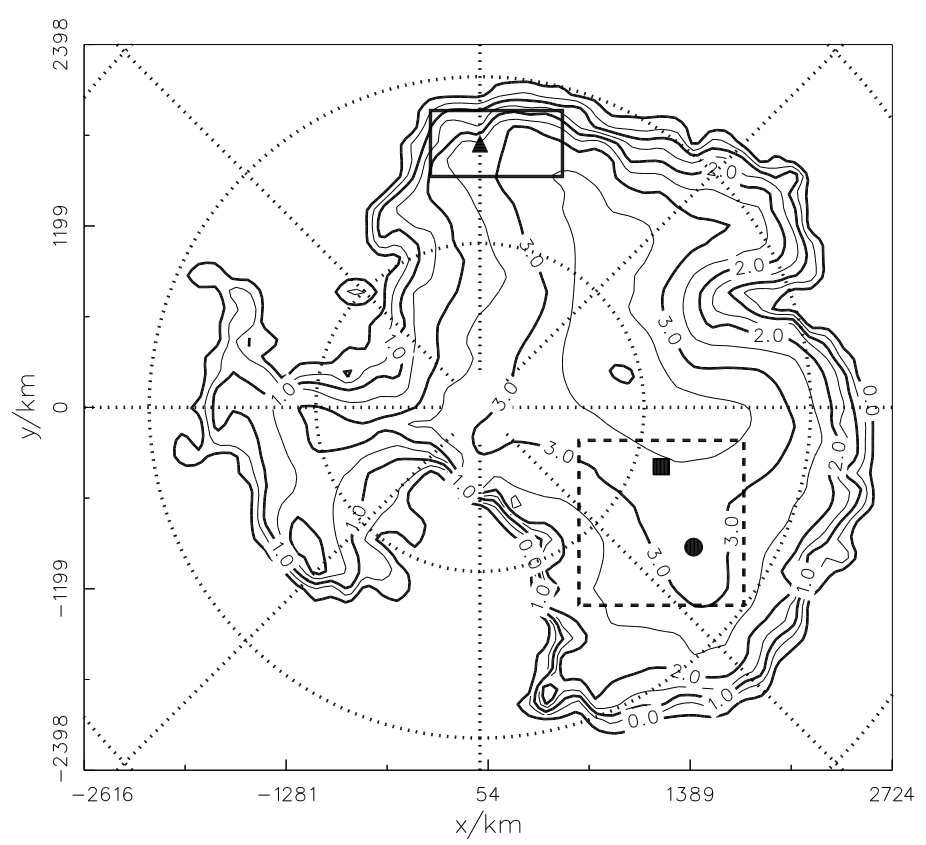

Fig. 1. Surface topography of the modern Antarctic ice sheet, by Drewry [4] (without ice shelves; in $\mathrm{km}$ a.s.l., contour spacing $500 \mathrm{~m}$ ). Solid rectangle: DML; the small triangle within marks the proposal by Savvin et al. [20] for the EPICA drillsite position. Dashed square: Eastern part of central East Antarctica with the ice core positions Vostok (small square) and Dome C (small circle).

column. Time steps are 2.5 years for the dynamic evolution (topography, velocity) and 50 years for the thermodynamic evolution (temperature, water content, age).

\subsection{Nesting for Dronning Maud Land}

In order to provide model support for the planned EPICA core in DML, Savvin et al. [20] introduced a refined subgrid for the $872 \times 436 \mathrm{~km}$ rectangle shown in Fig. 1, which is also applied here. Horizontal resolution of the subgrid is $10.9 \mathrm{~km}$ (refinement factor 10), so that the subgrid domain is discretized by $81 \times 41$ grid points. It is coupled to the coarse grid by boundary conditions at its margin which are interpolated field quantities of the coarse grid, and, in turn, it gives back the computed topography to the coarse grid at positions where coarse-grid and refined-grid points fall together (Savvin, [19]). The time steps for the refined DML computations are 0.1 years for the dynamic evolution and 1 year for the thermodynamic evolution. 


\subsection{Eulerian age computation}

For the age of ice (the elapsed time since the ice particles settled on the surface as snowflakes), $A$, the purely advective (hyperbolic) evolution equation

$$
\frac{d A}{d t}=1
$$

holds ( $t$ is time, $d / d t$ denotes the material time derivative which incorporates ice movement), with the corresponding Dirichlet-type boundary condition

$$
A\left(z=h_{\text {acc }}\right)=0
$$

in the accumulation zones at the free surface $h_{\mathrm{acc}}(x, y, t)$. If regions of temperate ice exist, at the cold-temperate transition surface (CTS) the age is continuous.

Integration of Eq. (1) in the Eulerian frame of the numerical grid requires first to re-write it with the local time derivative $\partial / \partial t$ and explicit advection terms,

$$
\frac{\partial A}{\partial t}+v_{x} \frac{\partial A}{\partial x}+v_{y} \frac{\partial A}{\partial y}+v_{z} \frac{\partial A}{\partial z}=1+D_{\mathrm{A}} \frac{\partial^{2} A}{\partial z^{2}}
$$

where $v_{x, y, z}$ are the velocity components in $x$-, $y$ - and $z$-direction. In order to achieve stable integration, the artificial vertical diffusion term $D_{\mathrm{A}}\left(\partial^{2} A / \partial z^{2}\right)$ is added on the right-hand side [6,11], and for the diffusivity $D_{\mathrm{A}}$ the small value $5 \cdot 10^{-8} \mathrm{~m}^{2} \mathrm{~s}^{-1}$ is used.

As the type of the age evolution equation has now changed from hyperbolic to parabolic, artificial boundary conditions for the ablation zones of the free surface, $h_{\mathrm{abl}}(x, y, t)$, and the entire ice base, $b(x, y, t)$, must be prescribed. Following Greve et al. [7], we use the Neumann-type conditions

$$
\frac{\partial A}{\partial z}\left(z=h_{\mathrm{abl}}\right)=0, \quad \frac{\partial A}{\partial z}(z=b)=-\frac{m_{\text {age }}}{S_{\text {mean }}},
$$

where $S_{\text {mean }}=2.4 \mathrm{~cm}$ ice equiv. $\mathrm{a}^{-1}$ is the mean snowfall rate and $m_{\text {age }}=200$ the thinning factor.

The system (2), (3), (4) is integrated with an FTCS (forward time centered space) scheme and upstream discretization of the horizontal advection terms. This is the standard age computation method of SICOPOLIS; however, its disadvantage is that below approximately $85 \%$ depth the influence of the diffusion term overrides the solution of the physical equation (1), so that near the bedrock the results are not reliable (Calov et al. [2], Greve et al. $[7])$.

\subsection{Lagrangian age computation (particle tracing)}

The Eulerian age computation does not make efficient use of the very simple nature of Eq. (1). In the Lagrangian frame which follows the ice particles, 
this equation can be discretized in a straightforward way without any artificial diffusion, and its solution becomes trivial. The numerical work in this approach is to find out for which positions in the ice body the solution holds, that is, to compute the particle paths $\boldsymbol{x}(t)$ ( $\boldsymbol{x}$ is the position vector, see Fig. 2). The corresponding evolution equation is

$$
\frac{d \boldsymbol{x}}{d t}=\boldsymbol{v}(x, y, z, t)
$$

where $\boldsymbol{v}$ denotes the velocity field in the ice sheet.



Fig. 2. Path of an ice particle through an ice sheet, starting from the deposition point $\mathrm{A}$ on the surface, along the positions $\mathrm{B}, \mathrm{C}, \mathrm{D}$, until position $\mathrm{E}$ where the particle leaves the ice sheet by melting or calving.

The system of equations (1), (2), (5) is now solved directly in the cold-ice domain (temperature below pressure melting). We exclude the small regions of temperate ice for numerical simplicity, and because the presence of liquid water disturbs the well-defined stratigraphy anyway. The solution of Eq. (1) is very simple and leads to the statement that in one year an ice particle becomes one year older. However, the integration of Eq. (5) requires more numerical effort, it is performed by the conventional fourth-order RungeKutta scheme (Törnig \& Spellucci [22]). The initial condition for Eq. (5) is that the trajectory of an ice particle deposited at time $t_{0}$ in the accumulation zone of the ice sheet starts at the free surface, that is

$$
\boldsymbol{x}\left(t_{0}\right)=\left(x_{0}, y_{0}, z=h_{\mathrm{acc}}\left(x_{0}, y_{0}, t_{0}\right)\right) .
$$

The end of a trajectory is reached when the ice particle leaves the cold-ice region by either crossing the free surface from below (ablation), or crossing the ice base (basal melting) or the CTS (if the cold ice is underlain by a layer of temperate ice). Further, for numerical reasons the tracing of a particle trajectory is stopped when the particle reaches a region with less than $500 \mathrm{~m}$ ice thickness, which occurs close to the margin of the ice sheet. 
Evidently, in order to solve Eq. (5) for particle trajectories, the threedimensional velocity field $\boldsymbol{v}(\boldsymbol{x}, t)$ as well as the topography (free surface, bedrock, CTS) of the ice body must be known. As SICOPOLIS provides these quantities only at the nodes of the numerical grid, which, in general, do not fall together with the positions $\boldsymbol{x}$ of the traced particles, a suitable interpolation procedure must be applied. For this, we use the values of the nearest-neighbour grid points and average them with weights proportional to the inverse distance to the position $\boldsymbol{x}$.

In this study, the particle-tracing algorithm is run diagnostically with the SICOPOLIS output for the modern time slice only. This implies that the time dependence of the velocity and topography is neglected, and we compute trajectories and ages in a quasi-steady-state approximation based on modern streamlines instead of real trajectories. In order to avoid interpolating the spatially-scattered particle ages back on the numerical grid, the algorithm is further run backward in time, that is, the particles of any ice column whose age is computed are traced back to the ice surface by applying the negative velocity field. As a by-product this method yields the geographic origin of the ice in a given column.

Full coupling between SICOPOLIS and the particle-tracing algorithm with consideration of the time-dependent velocity field and re-interpolation of the computed ages from the cloud of particles on the numerical grid has not yet been implemented. This will be done in the near future.

\subsection{Simulation set-up}

The present state of the Antarctic ice sheet is modelled as the result of a paleoclimatic simulation from 242200 years BP until today, initialized by a previous 100000-year steady-state run for the conditions at 242200 years BP. The simulation is driven by surface-temperature and sea-level histories derived from the Vostok ice core (Jouzel et al. $[13,15]$ ) and the SPECMAP sea-level record (Imbrie et al. [12]), respectively, and for the present reference state of the surface temperature the parameterizations given by Huybrechts [10] are used. The accumulation input is based on the modern dataset by Giovinetto, Zwally and Bentley (personal communication, 1997; publication in preparation), modified by a time-dependent factor coupled linearly to the surface-temperature deviation from today (Calov et al. [2]). Surface melting is modelled by a degree-day approach with the parameters $\beta_{\text {snow }}=3 \mathrm{~mm}$ w.e. $\mathrm{d}^{-1} \mathrm{~K}^{-1}$ (snow melt), $\beta_{\text {ice }}=8 \mathrm{~mm}$ w.e. $\mathrm{d}^{-1} \mathrm{~K}^{-1}$ (ice melt), $P_{\max }=60 \%$ (firn saturation rate) and $\sigma_{\text {stat }}=5^{\circ} \mathrm{C}$ (standard deviation for statistical air-temperature fluctuations) (Reeh [17]). Bedrock topography is by Drewry [4], complemented by recent high-resolution radio-echo-sounding data for DML measured and evaluated by the Alfred-Wegener-Institut für Polar- und Meeresforschung, Bremerhaven, Germany (Steinhage [21], Savvin et al. [20]). Further model parameters are listed in Table 1. 
The particle-tracing algorithm is fed by the topography and velocity field of the simulated present ice sheet, and it is integrated over 500000 years with a time step of 50 years. As explained above, this yields the age profiles for selected ice columns in quasi-steady-state approximation.

For the nested DML domain the particle-tracing method operates on the refined grid. Particle-tracing results in this region are therefore based on the $10.9-\mathrm{km}$ resolution instead of the coarse $109-\mathrm{km}$ resolution of the entire ice sheet.

Table 1. Physical parameters used in the simulation of the Antarctic ice sheet.

\begin{tabular}{ll}
\hline Quantity & Value \\
\hline gravity acceleration, $g$ & $9.81 \mathrm{~m} \mathrm{~s}^{-2}$ \\
density of ice, $\rho$ & $910 \mathrm{~kg} \mathrm{~m}^{-3}$ \\
power-law exponent, $n$ & 3 \\
rate factor, $A\left(T^{\prime}, \omega\right)^{1}$ & cold ice: Arrhenius law ${ }^{2}$ \\
& temperate ice: linear dependence on $\omega^{2}$ \\
flow-enhancement factor, $E$ & 5 \\
heat conductivity of ice, $\kappa$ & $9.828 e^{-0.0057 T[\mathrm{~K}]} \mathrm{W} \mathrm{m}^{-1} \mathrm{~K}^{-1}$ \\
specific heat of ice, $c$ & $(146.3+7.253 T[\mathrm{~K}]) \mathrm{J} \mathrm{kg}^{-1} \mathrm{~K}^{-1}$ \\
latent heat of ice, $L$ & $335 \mathrm{~kJ} \mathrm{~kg}^{-1}$ \\
Clausius-Clapeyron gradient, $\beta$ & $8.7 \cdot 10^{-4} \mathrm{~K} \mathrm{~m}^{-1}$ \\
basal sliding velocity, $\boldsymbol{v}_{\mathrm{b}}$ & cold base: no-slip \\
& temperate base: Weertman-type sliding \\
& $54.6 \mathrm{~mW} \mathrm{~m}^{-2}$ \\
geothermal heat flux, $q_{\mathrm{geo}}$ & $3 \mathrm{ka}^{2}$ \\
isostatic time lag, $\tau_{\mathrm{V}}$ & $3300 \mathrm{~kg} \mathrm{~m}^{-3}$ \\
asthenosphere density, $\rho_{\mathrm{a}}$ & \\
density $\times$ specific heat of the & $2000 \mathrm{~kJ} \mathrm{~m}^{-3} \mathrm{~K}^{-1}$ \\
lithosphere, $\rho_{\mathrm{r}} c_{\mathrm{r}}$ & \\
heat conductivity of the & $3 \mathrm{~W} \mathrm{~m}^{-1} \mathrm{~K}^{-1}$ \\
lithosphere, $\kappa_{\mathrm{r}}$ &
\end{tabular}

${ }^{1}$ Homologous temperature $T^{\prime}$ (relative to pressure melting), water content $\omega$ (mass fraction).

${ }^{2}$ For details see Greve et al. [7].

\section{Results and Discussion}

In the following we discuss age-depth profiles for the two ice cores Vostok, Dome C, and the EPICA DML drillsite proposed by Savvin et al. [20] (Fig. 1), computed with both the Eulerian and the Lagrangian particle-tracing method (henceforth referred to as "EM" and "PTM", respectively). For Vostok, the results can further be compared with the "Geophysical Metronome Time 
Scale" (GMTS) by Salamatin et al. [18], which was obtained by first inferring a surface-temperature history from the measured temperature profile by transient 1-d modelling, and then matching this history to the measured deuterium $(\delta \mathrm{D})$ profile.


Fig. 3. Simulated age profiles at (a) Vostok, (b) Dome C, (c) EPICA DML drillsite proposed by Savvin et al. [20]. Dashed lines: Eulerian scheme. Dotted lines: particletracing method. Solid line in panel (a): GMTS age profile by Salamatin et al. [18]. The origins of the vertical coordinate, $z=0$, correspond to the ice surface, the ice base is represented by the horizontal dotted lines.

Fig. 3a shows the age profiles computed with EM and PTM and the GMTS profile. The shape of the PTM curve agrees well with GMTS; however, it provides ages by approximately one third smaller. This difference can be explained with the quasi-steady-state assumption of PTM which uses only modern interglacial, rather large ice velocities to compute the age. In reality the deeper parts of the ice sheet have stored lower glacial temperatures and therefore smaller velocities, which leads to larger ages. By contrast, EM and GMTS agree quantitatively very well down to $1500 \mathrm{~m}$ depth due to the transient nature of the EM-based age computations. Further down EM yields much larger ages which reach as much as 780 ka at the base.

A similar behaviour becomes also evident for Dome C (Fig. 3b). Here EM and PTM fall closely together down to $1500 \mathrm{~m}$ depth, whereas further down EM ages become very (unrealistically?) large, and at the base the disagreement between the two methods reaches $500 \mathrm{ka}$. A probable explanation is that the applied thinning factor $m_{\text {age }}=200$ in the artificial basal boundary condition $(4)_{2}$, which does very well for Summit in central Greenland (Greve et al. [7]), is too large for central Antarctic locations. This points out very clearly the problem with the added numerical diffusion in the age equation (3) and the associated unphysical basal boundary condition.

For the EPICA DML drillsite proposed by Savvin et al. [20], situated at $73^{\circ} 59^{\prime} \mathrm{S}, 00^{\circ} 00^{\prime} \mathrm{E}$, the computed EM and PTM ages (Fig. 3c) agree better 
with each other than at Vostok and Dome C, the discrepancy at the base being approximately half of the values themselves. As the quasi-steady-state PTM ages tend to be somewhat too low in general (see above), the EM curve is probably more realistic also in the lower part of the ice column.

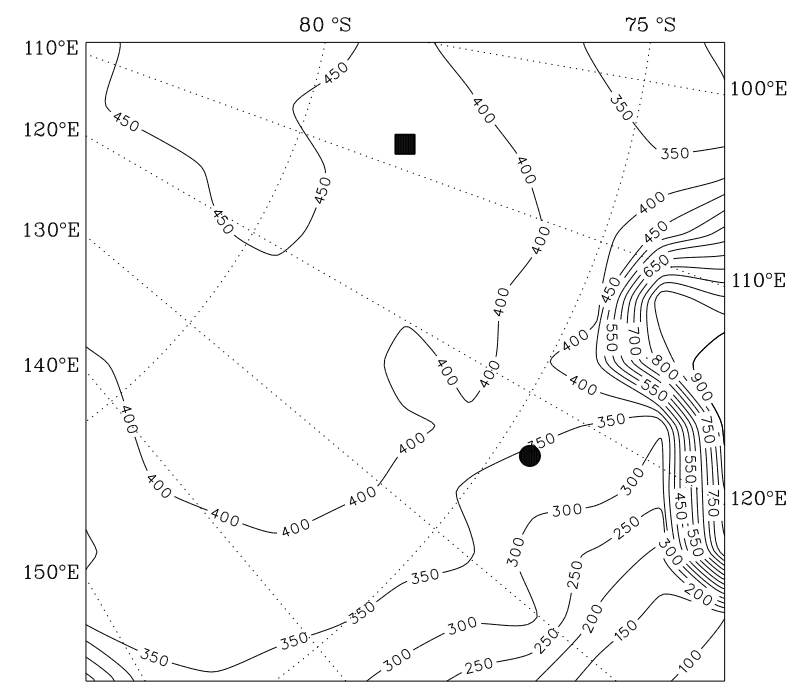

Fig. 4. Age at $85 \%$ depth (in ka) in the eastern part of central East Antarctica, computed with the Eulerian scheme. Square: Vostok. Circle: Dome C.

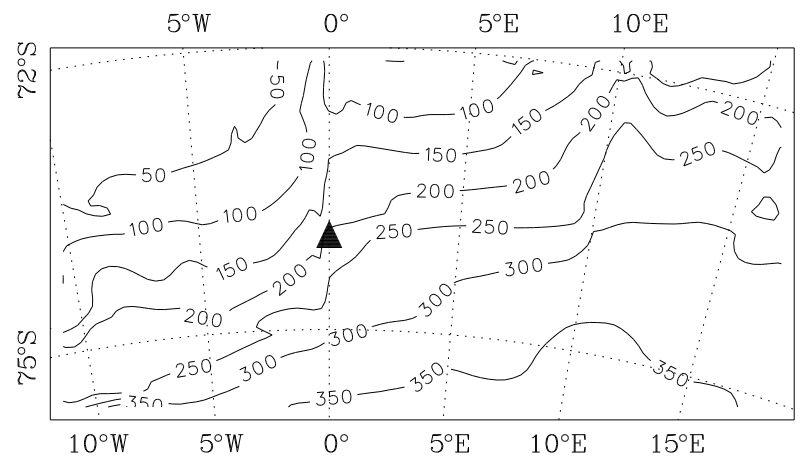

Fig. 5. Age at $85 \%$ depth (in ka) in DML, computed with the Eulerian scheme on the refined subgrid. Triangle: EPICA DML drillsite proposed by Savvin et al. [20].

In Figs. 4, 5 the EM ages at $85 \%$ depth are presented for the eastern part of central East Antarctica and DML, respectively. In the former case, the computed age is relatively uniform south of $75^{\circ} \mathrm{S}$ and decreases further north (coastward). A conspicuous exception to this is the zone between approximately $105^{\circ} \mathrm{E}$ and $125^{\circ} \mathrm{E}$ where the age increases sharply within a band 
of $150 \mathrm{~km}$ width, probably an effect of the Aurora and Vincennes subglacial basins in this region. By contrast, the computed DML age distribution shows a more even decrease from the ice interior to the coast.

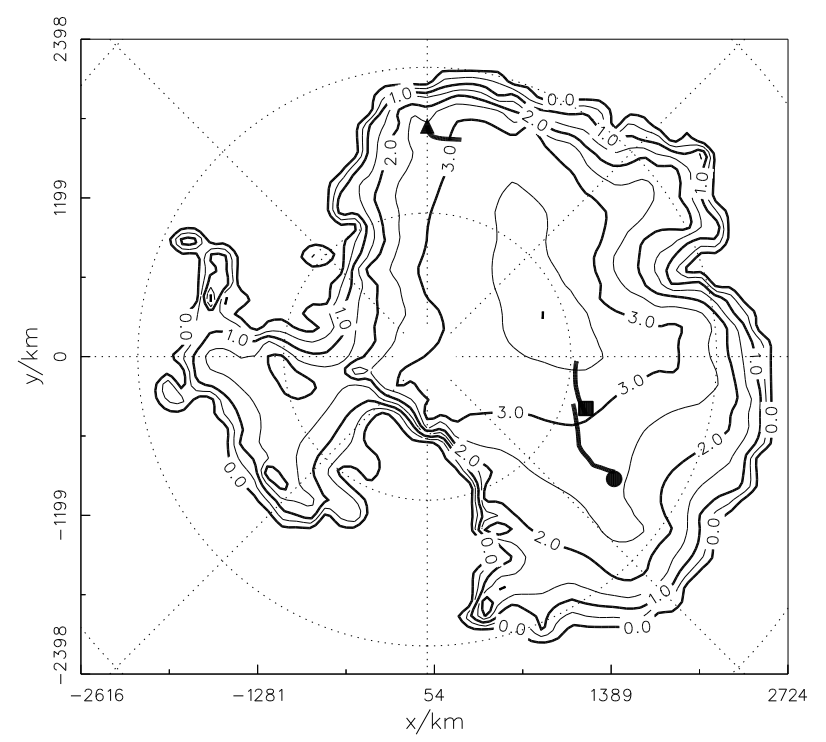

Fig. 6. Thick lines: Simulated geographical origin of the present ice columns at the EPICA DML drillsite proposed by Savvin et al. [20] (triangle), Vostok (square) and Dome C (circle). Background contours: simulated surface elevation, in km a.s.l.

A further interesting application of the particle-tracing method is to determine the geographical origin of a given borehole ice column, that is, the positions where the ice particles in the column were deposited on the surface as snowfall. Fig. 6 depicts the corresponding results for Vostok, Dome C and the EPICA DML drillsite proposed by Savvin et al. [20]. Evidently, for Vostok and Dome $\mathrm{C}$ the deeper ice was accumulated rather far from its present position, namely by approximately $500 \mathrm{~km}$ and $1000 \mathrm{~km}$ upstream toward Dome Argus (the highest point of the Antarctic ice sheet), respectively. However, the result for Dome $\mathrm{C}$ is doubtful because the local ice-elevation maximum is not reproduced by the simulation at this position, so that the simulated flow regime in the vicinity of Dome $\mathrm{C}$ is not that of an ice dome. For DML, the ice-origin line extends approximately $320 \mathrm{~km}$ upstream, so that the entire $2060 \mathrm{~m}$ thick column stems from within the DML domain marked in Fig. 1.

\section{Conclusion and Outlook}

Two numerical methods for the age computation in ice sheets, a Eulerian scheme with artificial diffusion and a Lagrangian particle-tracing scheme, 
were applied to the Antarctic ice sheet. The Eulerian scheme works well in the upper parts of the ice sheet, but becomes increasingly unreliable further down because of the influence of the numerical diffusion. The particle-tracing method circumvents this shortcoming; however, it has been implemented only in a quasi-steady-state mode by now which leads to an underprediction of the ages.

The particle-tracing method has the potential to yield very accurate solutions to the age evolution problem. The next step will be to replace the diagnostic, quasi-steady-state mode by a real coupling with the ice-sheet model SICOPOLIS so that the trajectories are computed on the basis of the time-dependent velocity field. This entails the necessity to interpolate the computed particle ages back on the numerical grid, which can be achieved by triangulation of layers with equal particle ages (isochrones) and vertical interpolation between those layers.

\section{Acknowledgments}

We thank H. Miller and D. Steinhage of the Alfred-Wegener-Institut für Polar- und Meeresforschung, Bremerhaven, Germany, for permission to use the radio-echo-sounding data of Dronning Maud Land. The support by the Deutsche Forschungsgemeinschaft under project no. Hu 412/19-3 is gratefully acknowledged.

\section{References}

1. Calov, R. and K. Hutter (1997) Large scale motion and temperature distributions in land based ice shields - the Greenland Ice Sheet in response to various climatic scenarios. Arch. Mech., 49 (5), 919-962.

2. Calov, R., A. Savvin, R. Greve, I. Hansen and K. Hutter (1998) Simulation of the Antarctic ice sheet with a three-dimensional polythermal ice sheet model, in support of the EPICA project. Ann. Glaciol., 27, 201-206.

3. Dansgaard, W. and S. J. Johnsen (1969) A flow model and a time scale for the ice core from Camp Century, Greenland. J. Glaciol., 8 (53), 215-223.

4. Drewry, D. J. (1983) Antarctica: Glaciological and geophysical folio. Scott Polar Research Institute, University of Cambridge.

5. Greve, R. (1997a) A continuum-mechanical formulation for shallow polythermal ice sheets. Phil. Trans. R. Soc. Lond., A 355, 921-974.

6. Greve, R. (1997b) Application of a polythermal three-dimensional ice sheet model to the Greenland Ice Sheet: Response to steady-state and transient climate scenarios. J. Climate, 10 (5), 901-918.

7. Greve, R., M. Weis and K. Hutter (1998) Palaeoclimatic evolution and present conditions of the Greenland ice sheet in the vicinity of Summit: An approach by large-scale modelling. Paleoclimates, 2 (2-3), 133-161.

8. Hutter, K. (1982) A mathematical model of polythermal glaciers and ice sheets. J. Geophys. Astrophys. Fluid Dyn. 21, 201-224. 
9. Hutter, K. (1993) Thermo-mechanically coupled ice sheet response. Cold, polythermal, temperate. J. Glaciol., 39 (131), 65-86.

10. Huybrechts, P. (1993) Glaciological modelling of the Late Cenozoic East Antarctic ice sheet: stability or dynamism? Geografiska Annaler, 75 A (4), 221-238.

11. Huybrechts, P. (1994) The present evolution of the Greenland ice sheet: an assessment by modelling. Global Planet. Change, 9, 39-51.

12. Imbrie, J., J. D. Hays, D. G. Martinson, A. McIntyre, A. C. Mix, J. J. Morley, N. G. Pisias, W. L. Prell and N. J. Shackleton (1984) The orbital theory of Pleistocene climate: Support from a revised chronology of the marine $\delta^{18} \mathrm{O}$ record. In: A. Berger et. al. (eds.), Milankovitch and climate, part I, D. Reidel Publishing Company, Dordrecht, Holland, 269-305 (NATO ASI Series C: Mathematical and Physical Sciences 126).

13. Jouzel, J. and 16 others (1993) Extending the Vostok ice-core record of paleoclimate to the penultimate glacial period. Nature, 364, 407-412.

14. Jouzel, J., K. Hammer, H. Miller, G. Orombelli, D. Peel and B. Stauffer (1994) European project for ice coring in Antarctica. Science Plan. [Available from Laboratoire de Modélisation du Climat et de l'Environnement, CEA/DSM SE Saclay, F-91191 Gif sur Yvette Cedex, France.]

15. Jouzel, J. and 14 others (1996) Climatic interpretation of the recently extended Vostok ice records. Climate Dynamics, 12, 513-521.

16. Mügge, B. (1998) Eisalterberechnung im antarktischen Eisschild mit einem Algorithmus zur Teilchenverfolgung. Diploma thesis, Institut für Mechanik, Technische Universität Darmstadt, Germany.

17. Reeh, N. (1991) Parameterization of melt rate and surface temperature on the Greenland Ice Sheet. Polarforschung, 59 (3), 113-128.

18. Salamatin, A. N., V. Y. Lipenkov, N. I. Barkov, J. Jouzel, J. R. Petit and D. Raynaud (1998) Ice core age dating and paleothermometer calibrations based on isotope and temperature profiles from deep boreholes at Vostok Station (East Antarctica). J. Geophys. Res., 103 (D8), 8963-8977.

19. Savvin, A. (1999) Grenzschichttheorie nichtlinearer Kriechströmungen und ihre Anwendung auf das EPICA-Vorhaben. Ph.D. thesis, Institut für Mechanik, Technische Universität Darmstadt, Germany (received 14 April 1999, accepted 28 April 1999).

20. Savvin, A., R. Greve, R. Calov, B. Mügge and K. Hutter (1999) Simulation of the Antarctic ice sheet with a 3-d polythermal ice-sheet model, in support of the EPICA project. Part II: Nested high-resolution treatment of Dronning Maud Land. Ann. Glaciol., 30 (submitted).

21. Steinhage, D. (1999) Ph.D. thesis in preparation, Alfred-Wegener-Institut für Polar- und Meeresforschung, Bremerhaven, Germany.

22. Törnig, W. and P. Spellucci (1990) Numerische Mathematik für Ingenieure und Physiker. Band 2: Numerische Methoden der Analysis. Springer-Verlag.

(Received 14 April 1999, accepted 16 April 1999) 